\title{
Impact of Education on the Quality of Life of Asthmatics: Evaluative Study of 100 Cases in Pneumophtisiology Department of the Fann National University Hospital Center (FNUHC), Senegal
} \author{
El Hadj Mamadou Ndiaye ${ }^{2}$, Samba Niang 3 , Thibaut Houssou ${ }^{2}$, Yacine Dia Kane', \\ Ansoumana Diatta ${ }^{4}$, Nafissatou Oumar Touré ${ }^{2}$ \\ ${ }^{1}$ Direction of FNUHC, Dakar, Senegal \\ ${ }^{2}$ Pneumophtisiology Department, FNUHC, Dakar, Senegal \\ ${ }^{3}$ Pneumology Department, Regional Hospital Center of Saint-Louis, Saint-Louis, Senegal \\ ${ }^{4}$ Department of Pneumology, Peace Hospital, Ziguinchor, Senegal \\ Email: ^thiamkhadie@yahoo.fr
}

Cheikh Tacko Diop" ${ }^{1}$ Khady Thiam ${ }^{2 *}$, Fatimata Binetou Rassoule Mbaye ${ }^{2}$, Maïmouna Fafa Cisse ${ }^{2}$,

How to cite this paper: Diop, C.T., Thiam, K., Mbaye, F.B.R., Cisse, M.F., Ndiaye, E.H.M., Niang, S., Houssou, T., Kane, Y.D., Diatta, A. and Touré, N.O. (2019) Impact of Education on the Quality of Life of Asthmatics: Evaluative Study of 100 Cases in Pneumophtisiology Department of the Fann National University Hospital Center (FNUHC), Senegal. Occupational Diseases and Environmental Medicine, 7, 1-12. https://doi.org/10.4236/odem.2019.71001

Received: December 5, 2018

Accepted: January 30, 2019

Published: February 2, 2019

Copyright () 2019 by author(s) and Scientific Research Publishing Inc. This work is licensed under the Creative Commons Attribution International License (CC BY 4.0).

http://creativecommons.org/licenses/by/4.0/

\section{c) (i) Open Access}

\begin{abstract}
Introduction: Therapeutic patient education is a continuous, integrated, patient-centered process. A study was conducted in the Asthma School in the pneumophtisiology department of Senegal. Overall goal was to determine the influence of therapeutic education on the quality of life of asthmatics. Method: Transverse study, descriptive and evaluative therapeutic education provided in the school of asthma on quality of life for asthma patients. Data were analyzed through IBM SPSS (Statistical Package for Social Science) version 20. Results: 100 asthmatic patients were included with a sex ratio of 0.37 . The average age of the patients was 36.76 years old. The majority $(81.3 \%)(n=39)$ being new participants. The average scores for symptoms, exposure to stimuli, emotions and limiting activities stay higher for adherent patients as well as the score overall quality of life. Conclusion: The school of asthma, associated with the therapeutic management, can improve the control of the disease and the quality of life of the patient.
\end{abstract}

\section{Keywords}

School of Asthma, Chronic Disease, Patient Cooperation, Non-Medicated Treatment of Asthma 


\section{Introduction}

Asthma is a multifactorial chronic condition involving genetic and environmental factors. Its pathogenesis revolves around bronchial inflammation, bronchial hyperreactivity and bronchial obstruction [1]. Therapeutic patient education has emerged over time as the best response element and especially the most viable to improve optimal care. This is how the places where the therapeutic education of the patient could be dispensed and the schools of asthma will be born all over the world [2] [3] [4]. According to the WHO "Therapeutic patient education is an ongoing process, integrated with care, and focused on the patient. It includes organized sensitization, information, learning and psychosocial support activities relating to the illness, prescribed treatment, care, hospitalization and other relevant care institutions and the health and illness behaviors of the patient. It aims to help the patient and their loved ones to understand the disease and the treatment, to cooperate with caregivers, to live as healthily as possible and to maintain or improve the quality of life. Education should make the patient capable of acquiring and maintaining the resources necessary to optimally manage his life with the disease" [5]. It is made in a frame called "School of Asthma". The latter is necessary for the management of asthmatic patients and should be integrated into the strategic plan for the fight against chronic noncommunicable diseases including bronchial asthma. It would be necessary, to be convinced, the Senegalese Society of Pneumology and the Ministry of Health. In this context, a school of asthma was set up, in December 2015, in the only Pneumophtisiology department of Senegal located at the FNUHC of Dakar. Subsequently, a descriptive et analytic study has been conducted to evaluate the impact of asthma school therapy education in the management of asthma. Overall goal was to determine the influence of therapeutic education on the quality of life of asthmatics. The specific objectives were to characterize the therapeutic education at the Pulmonology Department of FNUHC, to determine the socio-demographic data and the patients' antecedents, to compare the effect of therapeutic education within the school of asthma in the quality of life of adherent patients and new beneficiaries of therapeutic education.

\section{Method}

\subsection{Framework of Study}

This work was carried out within the Pneumo-phtisiologie Department, one of FNUHC Services, which is a Level 4 Public Health Institution. The service includes:

- An outpatient department, functional from Monday to Friday, from 08:00 to 17:00, which receives all-out patients including asthmatics.

- An area of reception of pneumological emergencies, functional from 17 to 8 hours and every weekends, where are taken care of the acute exacerbations of asthma. 
There are also weekly specialized consultations for monitoring asthmatic patients. Alongside this consultation, a therapeutic education of asthma is taking place.

\subsection{Type and Duration of Study}

It is a transversal, descriptive and evaluative study of the therapeutic education provided within the school of asthma on the quality of life of asthmatic patients. It was conducted from 01 April 2017 to 09 August 2017.

\subsection{Study Population}

The study included a global population of 100 asthmatic patients aged 18 years and over, divided into two independent groups. A first group, called "group of adherents" (PA) consisting of 30 asthmatic patients who participated at least in a therapeutic education session, recruited at their follow-up appointment and a second group called "group of new" (NP), made up of 70 patients received at the outpatient clinic, still naive, at the time of recruitment, of any participation in the therapeutic education program. All patients with no information approximately a therapeutic education were excluded.

\subsection{Collection of Data and Parameters Studied}

The data were collected by direct questioning of patients after their free and informed consent and then collected on an anonymous questionnaire. The questionnaire focused on:

- socio-demographic characteristics;

- the patients' history;

- the quality of life score: The AQLQ (Asthma Quality of Life Questionnary) mini, which is a validated version of the standardized AQLQ that is well correlated with the latter. This is a specific questionnaire for asthmatics, consisting of 15 questions included in 4 items:

- The symptoms felt (5 questions)

- The emotional function (3 questions)

- The environment (3 questions)

- Activity limitation (4 questions)

\subsection{Data Entry and Analysis}

The data were entered using the Excel $^{\circledR} 2010$ software. The analysis were done using the IBM SPSS (Statistical Package for Social Science) software version 20. The quantitative variables were described according to their position parameter and dispersion. The comparison of the quantitative variables were made with the Student's test according to the cases. The qualitative variables were expressed in proportion. They were compared using Pearson's Khi-2 or Fisher tests according to their applicability condition. Any difference were considered statistically significant for a p-value less than 0.05 . 


\section{Results}

\subsection{Sociodemographic Data}

During the study period (01st April 2017 to 09th August 2017), 100 asthmatic patients were included in total, including 30 adherents and 70 new patients. The population consisted of 73 women (73\%) and 27 men (27\%), a sex ratio of 0.37 . The average age of patients was 36.76 years with extremes of 18 years and 77 years. The most represented age group was that of [17 - 27 years old] with 35\% or a population of 35 . Subjects aged 65 and over accounted for $5 \%$ of the study population. Sample consisted of 53\% married, 30\% single, $10 \%$ divorced and $7 \%$ widowed. More than half of sample, 56\%, consisted of untrained patients (31\%) and primary school-educated patients $(25 \%)$. Approximately $54 \%(n=16)$ of the adherents consisted of these patients at the lower secondary level. Nearly half of the population, $49 \%(\mathrm{n}=49)$, had no income-earning activity and therefore received support from a family member. There were 15 patients in training (students and students). Of the 51 patients in paid occupations, $31.4 \%(\mathrm{n}=16)$ were in the formal sector and $68.63 \%(n=35)$ were in the informal sector. More than half of them $(64.7 \%, \mathrm{n}=33)$ had a monthly income greater than 2 times the SMIG. The $97 \%(n=97)$ of the population resided in the commune of Dakar and its suburbs. Table 1 reports sociodemographic data.

\subsection{Antecedents}

The duration of disease progression was more than 10 years for $48 \%$ of patients, the majority $(81.3 \%)(n=39)$ being new participants.

There were 04 smoking patients who smoked an average of 7 pack-years. Three patients had previous pulmonary tuberculosis.

Seven patients had comorbidity associated with their asthma. It was HTA ( $\mathrm{n}=$ $4)$ and sickle cell disease $(n=3)$. Table 1 reports patients antecedents.

\subsection{Quality of Life Score in both Patient Groups}

\subsubsection{Symptoms}

Shortness of breath: the average score was 5.67 for adherent patients and 4.63 for new patients. The difference was statistically significant with a p-value at 0.01 .

Cough embarrassment: the average score was 5.47 for adherent patients and 4.01 for new patients. The difference was statistically very significant with a p-value of 0.001 .

Experimentation of thoracic oppression: the average score was 5.63 for adherent patients and 4.71 for new patients. The difference was statistically significant with a p-value at 0.02 .

Alteration of night-time sleep: the average score was 6.20 for adherent patients and 5.06 for new patients. The difference was statistically very significant with a p-value of 0.005 . 
Table 1. Socio-demographic and clinicals charactristics in the two groups of adherent patients and new patients.

\begin{tabular}{|c|c|c|c|c|}
\hline & \multirow[t]{2}{*}{ Variables } & \multirow[t]{2}{*}{ Modality } & \multicolumn{2}{|c|}{ Percent (\%) } \\
\hline & & & PA & NP \\
\hline & & {$[17-27]$} & 36.67 & 34.29 \\
\hline & & [27-37] & 26.67 & 30.00 \\
\hline & & {$[37-47]$} & 3.33 & 14.29 \\
\hline & Age groups (years) & {$[47-57]$} & 23.33 & 12.86 \\
\hline & & [57-67] & 6.67 & 4.29 \\
\hline & & {$[67-77]$} & 3.33 & 4.29 \\
\hline \multirow{13}{*}{$\begin{array}{c}\text { Sociodemographic } \\
\text { Data }\end{array}$} & & Married & 56.67 & 51.43 \\
\hline & & Unmarried & 30.00 & 30.00 \\
\hline & & Divorced & 3.33 & 12.86 \\
\hline & & Widower & 10.00 & 5.71 \\
\hline & & Primary level & 26.67 & 24.29 \\
\hline & Education level & Secondary level & 30.00 & 24.29 \\
\hline & & University level & 16.67 & 18.57 \\
\hline & & $<$ GMIS & 8.33 & 17.95 \\
\hline & $\begin{array}{l}\text { Income according to } \\
\text { Guaranteed minimum }\end{array}$ & 1 - 2GMIS & 0.00 & 25.64 \\
\hline & $\begin{array}{c}\text { interprofessional salary } \\
\text { (GMIS) }\end{array}$ & 2 - 3GMIS & 50.00 & 20.51 \\
\hline & & $\geq 3$ GMIS & 41.67 & 35.90 \\
\hline & & $<1$ year & 5.70 & 5.80 \\
\hline & & $1-5$ & 5.93 & 6.04 \\
\hline \multirow[t]{3}{*}{ Medical data } & $\begin{array}{c}\text { Desease progression } \\
\text { (year) }\end{array}$ & $5-10$ & 5.87 & 5.00 \\
\hline & & $10-15$ & 6.10 & 6.10 \\
\hline & & $\geq 15$ & 6.00 & 4.35 \\
\hline
\end{tabular}

Experimentation of wheezing: the average score was 6.10 for adherent patients and 4.75 for new patients. The difference was statistically very significant with a p-value of 0.005 .

The mean score for the symptoms was 5.74 for adherent patients and 4.80 for new patients. There was a statistically significant difference with a p-value of 0.02 .

\subsubsection{Exposure to Stimuli}

Exposure to dust: the average score was 4.47 for adherent patients and 4.67 for new patients. The difference was not statistically significant with a p-value at 0.80 .

Exposure to cigarette smoke: the average score was 5.70 for adherent patients and 5.80 for new patients. The difference was not statistically significant with a p-value at 0.90 . 
Exposure to air pollution: the average score was 5.93 for adherent patients and 6.04 for new patients. The difference was not statistically significant with a p-value at 0.90 .

The mean scores for stimulus exposure were 5.68 for adherent patients and 5.47 for new patients. The difference was not statistically significant with a p-value of 0.60 .

\subsubsection{Emotion}

Frustration: The average score was 5.87 for adherent patients and 5.00 for new patients. The difference was not statistically significant with a p-value at 0.20 .

Concern approximately unavailability of drugs: the average score was 6.10 in both adherent and new patient populations.

Worry approximately being asthmatic: the average score was 6.00 for adherent patients and 4.35 for new patients. The difference was statistically very significant with a p-value of 0.001 .

The average score for emotion was 5.83 for adherent patients and 4.69 for new patients. There was a statistically significant difference with a p-value of 0.02 .

\subsubsection{Limitation of Activities}

Supported activities: the average score was 5.31 for adherent patients and 3.73 for new patients. The difference was statistically very significant with a $\mathrm{p}$-value of 0.005 .

Moderate activities: the average score was 5.80 for adherent patients and 5.36 for new patients. The difference was not statistically significant with a p-value at 0.10 .

Social activities: the average score was 6.47 for adherent patients and 6.34 for new patients. The difference was not statistically significant with a p-value at 0.50 .

Work-related activities: the average score was 6.15 for adherent patients and 6.04 for new patients. The difference was not statistically significant with a p-value at 0.60 .

The mean scores for activity limitation were 5.93 for adherent patients and 5.37 for new patients. There was a statistically significant difference with a $\mathrm{p}$-value of 0.01 .

\subsubsection{Overall Quality of Life Score}

It averaged 5.79 in asthmatic patients adhering to therapeutic education and 5.08 in new patients. The difference was statistically significant with a p-value at 0.02 . Table 2 reports the mean scores for the various items of different components of quality of life in the two groups of adherent patients and new patients.

\section{Discussion}

\subsection{Sociodemographic Data}

100 asthma patients were collected over a period of 4 month which 30 members and 70 new patients with a female predominance in both groups, as reported in 
Table 2. Mean scores for the various items of different components of quality of life in the two groups of adherent patients and new patients.

\begin{tabular}{cccccc}
\hline variables & & & PA & NP & \\
\hline \multirow{5}{*}{ Symptoms } & S1 & breathlessness & 5.67 & 4.63 & 0.01 \\
& S2 & Cough embarrassment & 5.47 & 4.01 & 0.001 \\
& S3 & Experimentation of chest tightness & 5.63 & 4.71 & 0.02 \\
& S4 & Alteration of nocturnal sleep & 6.20 & 5.06 & 0.005 \\
\multirow{5}{*}{$\begin{array}{c}\text { Exposure to } \\
\text { stimuli }\end{array}$} & E1 & Experimentation of wheezing & 6.10 & 4.75 & 0.005 \\
& E2 & Exposure to dust & 4.47 & 4.67 & 0.80 \\
& E3 & Exposure to air pollution & 5.93 & 6.04 & 0.90 \\
& EM1 & Frustration & 5.87 & 5.00 & 0.20 \\
& EM2 & Concern approximately & 6.10 & 6.10 & 0.99 \\
& EM3 & Worry approximately being asthmatic & 6.00 & 4.35 & 0.001 \\
& A1 & Activities supported & 5.31 & 3.73 & 0.005 \\
\multirow{2}{*}{$\begin{array}{c}\text { Limitation } \\
\text { of activities }\end{array}$} & A2 & Moderate activities & 5.80 & 5.36 & 0.10 \\
& A3 & Social activities & 6.47 & 6.34 & 0.50 \\
& A4 & Work-related activities & 6.15 & 6.04 & 0.60 \\
\hline
\end{tabular}

the literature [6] [7]. This large number of patients collated reflects the high prevalence of asthma in regions. It is a disease that should be taken much more seriously in developing countries and should be a health priority. The average age of the population was 37, close to 38.5 years of Thiam [6]. It was higher than the average ages noted by Sy [8], Diallo [9] in Mali and Koffi [10] in Abidjan with respectively 35, 31 and 27 years old. Most of the patients were under 30 years old. This youth of this study population and predominantly female could be explained by data from the General Census of Population and Housing, Agriculture and Livestock (GCPHAL) 2013 by the National Agency of Statistics and Demography [11] which showed an average age of 22.7 years of the Senegalese population. It has also been shown that asthma is a disease of young people in full activity and has a significant socio-economic impact in an already poor country.

Nevertheless, it is described in the elderly, especially in the Thiam study [6] which noted 5\% of asthmatics aged over 65 years. This may explain their participation in therapeutic education. Asthma of the elderly is a growing concern because of its singularities, including the importance of indirect extrarespiratory signs with an impairment of quality of life [12]. The study population was mostly married at 53\%. This shows the strong participation of his subjects despite the responsibilities related to the marital status of "married", especially among women in Muslim country.

More than half of the adherent patients (54\%) were educated at the primary or 
secondary level. These results reflect the still high illiteracy rate $(54.6 \%)$ in Senegal [11], which can constitute a brake on therapeutic education in african country. In fact, the teaching techniques and instruments mentioned in the various international recommendations are very poorly suited to subjects with a low level of education. Their successful implementation requires a certain range of intellectual skills and abilities [9]. Nearly half of the population (49\%) did not have any income-earning activity and therefore received support from a family member. Nearly one-third $(n=15)$ were trainees (students and students). In the group of members, $60 \%(n=18)$ did not have a profession. One third of the patients $(68.62 \%, \mathrm{n}=35)$ worked in the informal sector and $64.71 \%$ of them $(\mathrm{n}=$ 33) had an estimated monthly income of more than twice the SMIG. Asthma has a significant psychosocial dimension both in its distribution and in its management [9]. In fact, the Credes [13] observed, in a population of comparable age and sex, more asthmatic patients among the unemployed and inactive subjects than in the active population. Asthma was more prevalent among low-income households, regardless of the indicator chosen: income level, whether or not they received social assistance, and whether or not they had complementary coverage. Findings do not support evidence from the literature that having gainful employment influences the patient's sense of not being a burden to their family and society, which has a positive impact on their lives. Its ability to cope with the disease [9]. A recent Polish study published in March 2016, on the influence of socio-demographic factors, found a positive correlation between the exercise of a professional activity and all areas of the AQLQ [14]. This Study has shown, certainly, a small proportion of $40 \%$ of subjects in professional activity but should not forget that housewives are still in business. It is therefore important to consider the socioprofessional dimension of the asthmatic patient in the educational process. The majority of patients (72\%) came from the suburbs of Dakar. The study of the geographical distribution of patients is of interest in the characterization of asthma profiles, the influence of certain triggering factors including atmospheric pollution in the comparison of the disease in rural and urban areas. The Dakar region, because of its strong urbanization, is one of the polluted regions. The high density in population, more marked in the suburbs, is in constant increase and follows the curve of growth of the pollution.

\subsection{Antecedents}

Half of patients (48\%) had asthma for more than 10 years. Therapeutic education must concern all recent or old asthmatics especially when they are not controlled. It must be offered to all patients at the first consultation for asthma. Among patients who had asthma known for over 10 years, a majority $(81.25 \%, \mathrm{n}$ = 39) forestay $\mathrm{t} s$ new participants to school asthma. The latter is news in the management of asthma, which may explain why patients have been asthmatic for several years and do not benefit from a therapeutic education.

There were 04 smoking patients who smoked an average of 7 pack-years. Three patients had previous pulmonary tuberculosis. The low proportion of 
smokers among patients is an important asset in the care of patients. Active smoker's asthma is harder to control. HTA is very often associated with asthma as study and Thiam [6] have shown in studies. It is especially noted in the elderly and poses a real problem of differential diagnosis and management.

\subsection{Quality of Life Score}

\subsubsection{Symptoms}

The average scores for breathlessness, discomfort by coughing, chest tightness testing, alteration of nocturnal sleep and the former périmentation of wheezing were statistically higher among adherent patients.This difference was more important for cough discomfort, impaired nocturnal sleep, and wheezing. In contrast, mean scores for all symptoms were higher in new patients compared to adherent patients. These results mean that therapeutic education improves the symptoms experienced by asthmatics. Asthmatics are less cough-free, no longer experience wheezing, and have better sleep quality when receivingtherapeutic education, despite the fact that the average score for all symptoms does not follow the same direction. The data in the literature are quite unanimous on this subject. "Simplified" education programs or programs based solely on patient information do not reduce the frequency of hospitalizations, emergency room visits, unscheduled consultations, or absenteeism. They also do not improve respiratory function and medication use. On the other hand, they improve the symptoms, their perception by increasing their knowledge by the patient. These include randomized controlled trials selected by the Cochrane Library [15].

\subsubsection{Exposure to Stimuli}

Mean scores for exposure to dust, cigarette smoke and air pollution were higher in new patients, not statistically significant.

Overall mean scores for stimulus exposure followed the same trends but not significantly. Patients with therapeutic education are more familiar with the disease and its triggers. They are better aware of air pollution and preventative measures.

The chronic evolution of the disease for the most part involves a long course in hospitals, which, in turn, involves exposure to multiple therapeutic education interventions. Indeed, controlling the triggering factors of exacerbations including environmental stimuli is one of the most discussed lessons in consultations, hospitalizations and emergencies [15]. Thiam [6] noted that the most commonly identified and most prominent exacerbation triggers were frankincense (66.7\%), dust (65.1\%), tobacco smoke (59.0\%), 1\%) and air pollution (59.1\%).

\subsubsection{Emotion}

Mean scores for frustration were higher in adherent patients. The mean score was also statistically higher for anxiety approximately being asthmatic in adherent patients. Overall average scores for emotion were statistically higher among adherent patients. The emotion, especially the feeling of frustration and anxiety felt by asthmatics push them to want to better know their disease which they 
insist to adhere to the school of asthma. A better knowledge of the disease improves to a certain extent the patient's relationship with, and improves his ability to cope with it [9]. The results show that asthmatics are not sufficiently aware of the need for their medication.

\subsubsection{Limitation of Activities}

The average scores for the supported activities were statistically higher among adherent patients. The difference of the scores $s$ for moderate, social and work-related for both populations was not statistically significant.

Overall mean scores for activity limitation were statistically higher among adherent patients. Limiting the activities of asthmatic patients may be a reason for regularity in follow-up and adherence to therapeutic education.

Jankowska-Polańska et al. [16] in a recent Polish study support results by finding a positive correlation between therapeutic education and the imitation of the $(\mathrm{R}=0.21)$.

The benefits of physical activity in the management of asthma are addressed in the school of asthma and the ideas received are scanned at the same time .

\subsubsection{Overall Quality of Life Score}

It was statistically higher among asthmatic patients adhering to therapeutic education compared to new patients. The separate evaluation of the items in each quality of life component, the components themselves, and the overall quality of life score show an improvement in their score through therapeutic education in the school's classroom. asthma. These results demonstrate the usefulness of therapeutic education in the management of all asthmatics. This is in line with that of Jankowska-Polańska et al. [16]. A better knowledge of asthma through therapeutic education improves the symptoms and theirperception. The lighter the symptoms, the better the control of the disease and the better the quality of life. The school of asthma should be formalized and extended to all asthma management centers.

\section{Conclusion}

Asthma is a chronic bronchial condition characterized by paroxysmal bronchial hyperreactivity responsible for variable symptoms over time and unpredictable changes. It requires regular monitoring based in part on good adherence to the background therapy. The introduction of treatment and its compliance as well as the elimination of triggers on are fundamental elements for the prevention of exacerbations. This disease represents a major public health problem, for which it is now accepted that patient education is an integral part of care.

\section{Conflicts of Interest}

The authors declare no conflicts of interest regarding the publication of this paper. 


\section{References}

[1] Godard, P., Chanez, P., Bousquet, J., Demoly, P., Pujol, J. and Michel, F.-B. (1996) Asthmology. Elsevier Masson, Coll Abrégés de Médecine, Paris, 276 p.

[2] Bucquet, D., Condon, S. and Ritchie, K. (1990) French Adaptation of the "Nottingham Health Profile" and Operative Characteristics of the French Version. Inserm, Montpellier.

[3] Bousquet, J., Knani, J., Dhivert, H., Richard, A., Chicoye, A., Ware Jr., J.E. and Michel, F.B. (1994) Quality of Life in Asthma. 1. Internal Consistency and Validity of the SF-36 Questionnaire. American Journal of Respiratory and Critical Care Medicine, 149, 371-375. https://doi.org/10.1164/ajrccm.149.2.8306032

[4] Foucaud, J., Bury, J.A., Balcou-Debussche, M. and Eymard, C. (2010) Therapeutic Patient Education: Models, Practices and Evaluation. Inpes, Coll. Health in Action, Saint-Denis, $412 \mathrm{p}$.

[5] World Health Organization (1996) Therapeutic Patient Education: Continuing Education Programs for Healthcare Providers in the Field of Prevention of Chronic Diseases. WHO, Copenhagen.

[6] Thiam, K., Ndiaye, E.H.M., Dia Kane, Y., Mbaye, F.B.R., Touré, N.O., Diatta, A., Cissé, M.F., Niang, A. and Hane, A.A. (2012) Profiles Epidemiological, Clinical and Therapeutic Aspects of Asthma in a Consultation All Coming from Pneumology at the National University Hospital of Fann (CHEF) in Dakar. Memory Doct Med, UCAD, 590 .

[7] Diallo, S., Sissokho, B.F., Baya, B., Toloba, Y., Cayon, I. and Mbaye, O. (2009) Socio-Economic Impact of Asthma in Bamako on 131 Cases. Mali Medical, 24, 57-60.

[8] Sy, P.D. (2018) E Study of Factors Related to s Delay in Diagnosis and Management of Patients Asthma Received at the CHNUF Pneumology Consultation. Thes Doct Med, UCAD, 3.

[9] Koffi, N., Ngom, A., Kouassi, B., Horo, K., Gondola, P. and Aka-Danguy, E. (2001) Profile of Adult Asthmatics Followed in Consultation in Africa in Abidjan. Man, 48, 477-480.

[10] National Agency of Statistics and Demography (2014) General Census of Population and Housing. Agriculture and Livestock ANSD Report 2013.

[11] Radenne, F., Verkindre, C. and Tonnel, A.B. (2003) L'asthme du sujet âgé. Revue des Maladies Respiratoires, 20, 95-103.

[12] National Agency for Accreditation and Evaluation in Health (NAAEH) (2001) Therapeutic Education of Asthma Patient-Adults and Teens: Professional Recommendations and References Service, Paris, 129 p.

[13] Com. Ruelle, L., Crestin, B. and Dumesnil, S. (2000) Asthma in France According to the Stages of Severity. Credes, Paris.

[14] Uchmanowicz, B., Panaszek, B., Uchmanowicz, I. and Rosińczuk, J. (2016) Sociodemographic Factors Affecting the Quality of Life of Patients with Asthma. Patient Preference and Adherence, 10, 345-354. https://doi.org/10.2147/PPA.S101898

[15] Gibson, P.G., Powell, H., Coughlan, J., Wilson, A.J., Abramson, M., Haywood, P., Bauman, A., Hensley, M.J. and Walters, E.H. (2001) Self-Management and Regular Practitioner Review for Adults with Asthma (Cochrane Review). The Cochrane Library, Update Software, Oxford.

[16] Jankowska Polańska, B., Pleśniak, J., Seń, M., Uchmanowicz, I. and Rosińczuk, J. 
(2015) The Importance of Education in Bronchial Asthma Treatment-Gender Differences. Pneumonologia i Alergologia Polska, 83, 341-347.

https://doi.org/10.5603/PiAP.2015.0055 